\title{
Word Problems: Reflections on Embedding Quantitative Literacy in a Calculus Course
}

\section{Gizem Karaali}

Dept. of Mathematics, Pomona College, gizem.karaali@pomona.edu

Follow this and additional works at: https://digitalcommons.usf.edu/numeracy

Part of the Mathematics Commons, and the Science and Mathematics Education Commons

\section{Recommended Citation}

Karaali, Gizem. "Word Problems: Reflections on Embedding Quantitative Literacy in a Calculus Course." Numeracy 1, Iss. 2 (2008): Article 6. DOI: http://dx.doi.org/10.5038/1936-4660.1.2.6 


\title{
Word Problems: Reflections on Embedding Quantitative Literacy in a Calculus Course
}

\begin{abstract}
Even though Quantitative Literacy (QL) programs are currently being developed and implemented in several colleges and universities, most schools still depend on traditional mathematics courses to reach their quantitative literacy goals. This note is a case study of how a traditional mathematics course sequence intended for students majoring in social and life sciences may be modified and adapted to at least partially fulfill the need in the absence of a stand-alone QL program. In particular, we focus on a freshman-level mathematics course sequence that serves various client departments. This sequence covers the traditional content of a first-year calculus sequence along with a clear and intentional emphasis on word problems. The kinds of word problems used are not necessarily limited to those that require or make substantial use of a calculus background. However in this perspective we propose that various levels of word problems may be used successfully to satisfy QL goals. Descriptions of QL mainly focus on going from the mathematical data and presentations to an understanding of the real world. In this note we surmise that word problems go in the opposite direction and, in some sense, close the loop in QL.
\end{abstract}

\section{Keywords}

Quantitative Literacy (QL), word problems, calculus.

\section{Creative Commons License}

(c) (1) (9)

This work is licensed under a Creative Commons Attribution-Noncommercial 4.0 License 


\section{Prelude}

When I first described this note to a colleague, he mentioned a Gary Larson cartoon with the caption "Library in Hell." I dutifully went home and found my enormous Far Side album. Indeed, there it was, in the second volume (Larson 2003) on page 78: A whole bookcase full of books, and The Devil right there in the background, with an insanely cruel smile on his face. All the book titles involved "Story Problems."

\section{Introduction}

Some ten years ago, a committee of the Mathematical Association of America (MAA) prepared a report (Sons 1996) focusing on quantitative reasoning requirements for college graduates. This study culminated in a list of common goals and ideals and encouraged colleges and universities to view quantitative literacy (QL) as a thoroughly legitimate and even necessary goal for undergraduate level education.

The report (in its Part 2) identified a quantitatively literate person as one who could

- "interpret mathematical models such as formulas, graphs, tables, and schematics, and draw inferences from them.

- "represent mathematical information symbolically, visually, numerically and verbally.

- "use arithmetical, algebraic, geometric and statistical methods to solve problems.

- "estimate and check answers to mathematical problems in order to determine reasonableness, identify alternatives, and select optimal results.

- "recognize that mathematical and statistical methods have limits."

Since that report, the discussion around the goals and logistics of QL has grown to include a variety of participants and many diverse threads of ideas. The Special Interest Group of the MAA in Quantitative Literacy (SIGMAA-QL) maintains a Web site ${ }^{1}$ full of interesting and relevant resources for background on the field. Madison and Steen (2008) have summarized the historical development of the concept. The National Numeracy Network has launched this online journal.

One of the recommendations of the MAA committee (Sons 1996) was that colleges and universities develop a quantitative reasoning program where students

${ }^{1}$ http://www.maa.org/sigmaa/ql/ (accessed June 11, 2008). 
at each level would participate in some coursework emphasizing quantitative reasoning. At the present time, although several schools have adopted this recommended policy by developing stand-alone QL programs (Madison and Steen 2008), most colleges and universities still depend on traditional mathematics courses offered by their mathematics departments to serve this purpose. In most cases, such courses are presented to the students in the form of fixed requirements to be fulfilled. Students do not always understand how these requirements (e.g., a college algebra course or a calculus sequence) may benefit them in relation to their major and their future career plans. Therefore, at least some of the students view such courses as mere obstructions along their paths to their main goal, the degree, and see the material in these courses as irrelevant to their personal and professional development. These attitudes commonly result in less-motivated students and low long-term retention rates of the main concepts introduced in the courses. ${ }^{2}$

In this note, I will discuss how such a traditional course required by various departments as a prerequisite for acceptance into their majors may still be useful for the purpose of developing quantitative reasoning skills. The particular experiences I refer to here are related to my own teaching at the University of California, Santa Barbara (UCSB). The course I focus on is the two-quarter sequence of MATH 34AB, entitled Calculus for Social and Life Sciences.

As the nature of this note is clearly and necessarily anecdotal, ${ }^{3}$ I claim no general rules and make no sweeping assertions. However I hope that this Perspective will encourage further discussion of incorporating the principles of QL into already existing lower-division mathematics courses that aim to serve client departments.

\section{The Course}

The department of mathematics at UCSB currently offers two different basic calculus sequences. One is the MATH $3 \mathrm{ABC}$ sequence, which is required for most of the mathematical and physical sciences and engineering majors. The other is the MATH 34AB sequence, which is the course sequence that makes up the theme of my discussion. The catalog description (UCSB 2004) for this sequence is as follows:

\footnotetext{
${ }^{2}$ This is a common interpretation of general student apathy by faculty teaching such required courses, and in general no specific evidence is provided to justify it. However, in this particular case, students themselves verified this sentiment; see the results of the in-class survey discussed under "Student Expectations."

${ }^{3}$ UCSB is currently attempting to revise its introductory and service-level mathematics courses, and therefore, this note will soon be historical as well as anecdotal.
} 
MATH 34A: Introduction to differential and integral calculus with applications to modeling in the biological sciences.

MATH 34B: Continued study of differential and integral calculus with applications. Introduction to mathematical modeling with differential equations. Calculus of several variables including an introduction to partial derivatives.

This course sequence is required for students who wish to declare majors in a variety of areas such as psychology, environmental studies, biological sciences, and business economics. In most cases, students will not need to take another course with a substantial quantitative component before graduation, while in other cases, options emphasizing such courses may be available (e.g., in business economics, a student may wish to obtain a degree with an emphasis in accounting).

While I was at UCSB, none of the courses we offered fit the description of a program exclusively intended to promote QL. UCSB was one of those institutions that still relied on traditional courses offered by their mathematics departments for this purpose. The client departments needed to utilize what was being offered. The MATH 34 calculus sequence thus became a weed-out course (common knowledge among prospective psychology majors, for example), as well as the main quantitative component of many a student's college education.

UCSB is a major state university, and several introductory classes are run as large lecture courses augmented by weekly discussion sections run by graduate student teaching assistants. During Fall 2004, I taught two large sections of MATH 34A in precisely this format. I was the main lecturer for a total of 245 students during this time. During Winter 2005, I taught a single lecture section of MATH 34B. I had 107 students in this class. In both cases I had the help of graduate student instructors (three in the fall, one in the winter) who ran weekly discussion sections where they worked on homework problems and sample exercises. In each quarter, there was a second instructor running a separate lecture section of similar size.

\section{The Text}

The text used for the MATH 34AB sequence was Calculus and Mathematical Reasoning for Social and Life Sciences (Cooper 2000). Daryl Cooper of the UCSB mathematics department wrote the text after consulting with the departments that require their majors to take this sequence. The content of the text 
(and equivalently the material to be covered in the course sequence), therefore, was determined mainly by the utility to the client departments.

Cooper's book naturally splits into three parts:

- Review of basic mathematical skills: a review of algebra (Chapter 1), a short chapter on graphs (Chapter 2), a section discussing unit systems and conversions between units, and ideas of growth and size (Chapter 4), a review of linearity and basic analytic geometry (Chapter 6), and a (long) chapter on logarithms and exponentials (Chapter 7). All except Chapter 7 are meant to be covered quickly as students are expected to be familiar with most of this material.

- Calculus: a chapter on preliminaries for calculus, including the concepts of error and limits (Chapter 5), an introduction to derivatives and differential calculus (Chapter 8), a basic section on integration (Chapter 9), a chapter on further topics related to differential calculus, including material on trigonometric functions (Chapter 12), a chapter on differential equations (Chapter 13), and a short section on multivariable calculus (Chapter 15). This part provides the basics of calculus necessary for the client departments.

- Quantitative reasoning and analytical thinking: a basic introduction to mathematical modeling and word problems (Chapter 3), a long list of word problems (Chapter 11), and a chapter on how to study mathematics and science courses and more generally how to approach quantitative subjects and problems (Chapter 16). Especially Chapter 16 is meant for self-study, but using some class time on word problems will help students benefit from these sections of the book.

In a typical two-quarter terminal calculus sequence intended for students majoring in social and biological sciences, instructors end up cutting many corners. Several topics standard in a regular calculus sequence (e.g., special methods of integration like trigonometric substitution) do not in general make the final cut. Cooper's text presents the bare-bones basics of calculus, and leaves some such material out. However, compared to other texts for a similar audience, it covers approximately the same ground in calculus. In particular, my MATH 34 students learned a good amount of calculus in these two terms.

The main difference between Cooper's book and other calculus texts serving similar audiences is its emphasis on quantitative reasoning and analytical thinking - and its focus on word problems. Cooper explains the relevance of this material in his introduction to the text. He emphasizes that in his book he uses word problems to develop the students' logical reasoning and analytical thinking skills, 
and to strengthen their ability to handle novel problems by using these skills. He adds that developing these skills will be the most useful component of this course sequence for the students (Cooper 2000, p. 2).

While reviewing the description above of the contents of Cooper's text, readers of this note may notice that the sections on word problems, reasoning and modeling are separate from the rest of the text. It might be tempting, therefore, to assume that these sections can be skipped altogether. On the contrary, Cooper clearly intends that they be integrated into the course. Even the title of the text embodies this intention. Moreover, the fact that the word problems are all lumped together allows the instructor to use them as she desires.

With its focus on mathematical reasoning and word problems as a means to the end of developing students' ability to extricate mathematical information from the written word, Cooper's textbook aims to provide the students with a path towards QL. ${ }^{4}$ Therefore, the MATH 34AB courses, which use this book, present us with a good example of a compromise between a traditional calculus sequence and a general-education QL sequence for schools that have not developed an independent QL program.

\section{Student Expectations}

While teaching Math 34AB during the Fall 2004 and Winter 2005 terms, I became interested in the various backgrounds and expectations that my students were bringing to my class and decided to try to find out about them. ${ }^{5}$ I could easily notice a common thread: This is a required course sequence, and students take it only because they have to. Only three out of the sixty students who responded to a survey ${ }^{6}$ during the second course (Math 34B) said that they were taking the course "to satisfy general interest" as opposed to merely "satisfying a requirement".

This resignation reflected clearly in the motivation and interest of the students: Among the same sixty students, twenty-six noted that even before taking the course, their interest level in the subject was low or very low. Another twenty-

\footnotetext{
${ }^{4}$ Some may disagree with my interpretation of Cooper's use of word problems as a means to developing QL. I explain my reasoning in a later section. I do not know whether Cooper himself has ever made such a claim.

${ }^{5}$ My study was entirely informal. A more robust study could compare attitudes of my students with the general attitudes detected via the Dartmouth MATC surveys, which can be found online at http://www.math.dartmouth.edu/ matc/Evaluation/humeval.pdf (accessed Jun 10, 2008)

${ }^{6}$ There were a total of 107 students enrolled in the course. The survey was given during one of the lecture hours. Attendance in lectures was not required. Thus the survey responses may be skewed toward more-interested and/or responsible students.
} 
two rated their initial interest as average, and there were only twelve individuals who rated their initial interest as high or very high.

The general attitude of the students towards mathematics as discerned from this survey is also worth mentioning. At the end of the survey, the students were asked to choose between the following four statements:

- I have always been good at and felt comfortable with mathematics.

- I always have done sufficiently well in my mathematics courses, but do not really feel I am good at it.

- I did not do that well in mathematics before, but I think it may be different this time.

- I never seem to do well in mathematics even if I work hard, so I do not care anymore.

They also had the alternative to respond with a statement of their own.

While ten students chose to describe their attitude by their own words, an overwhelming number of those who picked among the four statements decided on the second statement. Thirty-three out of fifty students declared in this anonymous survey that despite the fact that their previous performance in mathematics was always satisfactory, they never felt confident about matters mathematical. Eight out of the ten that chose to write their own statements mentioned serious worries about their performance in mathematics. Overall, most students had unpleasant feelings about their previous mathematical experiences and many of them did not expect this to change. Even students who consistently performed well in mathematics had math anxiety.

Another expectation that surfaced in this survey and other forms of student feedback was the expectation that the course should be limited to calculus. Students were uncomfortable at first with the emphasis on word problems, which most saw as unrelated to the purposes of the course. In fact, most of them perceived the aim of the course as teaching/learning calculus, namely the various techniques of differentiation and integration, and nothing more.

Tangential but related to this lack of understanding of the actual scope of the course sequence was the students' tendency to compartmentalize their mathematical knowledge and experience. Most students were comfortable with saying that they have never been good at trigonometry, but are good at algebra or vice versa. Several such comments appeared in the in-class survey mentioned above. I also received some similar comments during office hours. Another issue came up in their reactions to some problems we solved in class. Almost all the students were annoyed when asked to use certain facts that they had happily left 
behind in their high school mathematics classes, e.g., the formulas to find the circumference of a circle, or the volume of a cylinder. The cumulative nature of mathematical knowledge was certainly not obvious to my students.

\section{The Class}

As the book we used was developed especially for this course sequence, my syllabus was parallel to the table of contents. The word problems were all in Chapters 3 and 11, but I believe that the most beneficial way to use them is to keep students working on word problems throughout the term. As a result, I ended up doing a healthy amount of hopping around in the text.

Word problems were introduced in lecture during the second week of classes in MATH 34A. After that, I made sure to solve at least one word problem explicitly in lecture every class meeting. I included some word problems in all the homework assignments starting with the second one. I put at least five word problems on each homework set. There were word problems on each of the two midterms and on the final. Word problems were still emphasized in MATH 34B. With only one exception, each homework assignment in that course contained at least three to four word problems. The midterm and the final exams included word problems along with traditional calculus questions. In all, the sequence included $9+8=17$ homework assignments that included 96 word problems.

In class, I introduced and solved various types of word problems regularly, with the specific intention of showing students how to think through solving a problem. I insisted that the students present their work in a very stratified manner; this allowed them to follow the step-by-step procedure developed in their textbook. Even though I had some (expected) complaints from some of the stronger students early on, this strategy worked out well for everyone in the end.

According to the procedure provided in the textbook, students would start by stating the goal of the problem as determining the value of a particular quantity (STEP 1: focus on what you are being asked). Next they would pick variables that denoted the quantities that they might need to solve the problem and define them (STEP 2: define your terms). After that, they would draw a picture if possible (STEP 3: visualize). The next step would be to use the variables defined to translate the information given in the problem into mathematical form (STEP 4: write down what you know). At this point students only needed to go and figure out how to solve for the variable that represented the quantity that they had isolated as their goal (STEP 5: do the math). Last but not the least, they had to go 
over their solution and see if their answer made sense (STEP 6: check your answer). ${ }^{7}$

Cooper's book also requires student responses to the word problems to be given in full and grammatically correct sentences. When I taught MATH 34AB, I did not focus on this aspect as much as I could have. This was because I found that, for many students in my classes, just figuring out the general systematics of attacking a word problem by itself, without focusing necessarily on the presentation of the final result, proved to be a serious challenge. However some of the instructors wanting to use word problems for the purpose of infusing QL into their course may also be interested in adding such a writing component to it. This is an interesting connection to investigate though not within the scope of this particular note. ${ }^{8}$

In the next section we discuss word problems in some detail. However, a point that needs to be made sooner rather than later is the following: The kinds of word problems used in these two courses were not necessarily the meatiest, or the most interesting ones. Many were in fact quite simplistic. The major difference of the courses described here from other standard calculus sequences is the emphasis on the solution process for a given word problem and the myriad kinds for the students to practice their newly developing skills at attacking word problems systematically.

\section{A Word on the Word Problems}

The word problems that were the main focus of this course sequence were not necessarily limited to those that required or made substantial use of a basic calculus background. In fact, many of them could very well have been accessible to students with no calculus experience. However, the inclusion of word problems in this course sequence was nonetheless very significant.

Daryl Cooper, who developed the course sequence described here, and wrote the textbook used in it, told me that in his conversations with the various client departments, he had been repeatedly told that those departments wanted their

\footnotetext{
${ }^{7}$ Readers familiar with Polya's How to Solve It (Polya 1957) will recognize the similarities of this strategy with Polya's four-step heuristic. Polya's first step is expanded into four steps in our strategy. His second and third steps in our case are put together under the heading of Step 5. His last step also coincides mostly with ours. See http://www.math.utah.edu/ pa/math/polya.html (accessed June 10 2008) for a summary of Polya's heuristic.

${ }^{8}$ Many have already investigated the idea of using writing in mathematics courses. Writing in the context of QL has also been studied recently. For some resources check out NNN's Web site at http://serc.carleton.edu/nnn/quantitative writing/index.html (accessed June 11 2008).
} 
students to have the ability to interpret numerical data and to translate such data into mathematical formulas. They also wanted their majors to be able to interpret various mathematical formulas, and understand what such formulas could tell them about relationships between variables. Then the client departments could comfortably focus on teaching discipline-specific material, utilizing extensively the basic mathematical-problem-solving and interpretation-of-quantitative-data skills of their majors.

These needs of the client departments, I expect, will resonate with those familiar with the discussions about quantitative literacy ${ }^{9}$. I think it is not a stretch to say that the client departments were basically asking for a QL course! In particular, the first two out of the five goals promoted by Sons (1996) as discussed in the Introduction fit almost word by word the wants and needs list of the client departments.

However, for various reasons these wants and needs had to be met at UCSB by a calculus sequence, if they were to be met at all. This is a common scenario in many institutions. For instance, medical schools expect some calculus proficiency in their applicants. Thus biology or pre-med majors need to have such an item saying "calculus" in their transcript. Even if future doctors will not integrate any functions using partial fractions in the course of their medical careers, they still are expected to have aced a calculus course or two in their undergraduate years. The focus of the MATH 34 sequence on word problems was intended to make this a calculus sequence which could also serve the other (QL-based) needs of the client departments.

Word problems present basic mathematical problems in a verbal setting. They force students to develop the ability to be able to extract numerical data from within a text and to interpret the text and the numbers in a way that allows them to formulate a mathematical problem that can be solved purely mathematically. In other words, they provide a perfect framework for students to practice their quantitative literacy skills.

Recall that the five goals of QL mentioned in the introduction mainly focus on going from the mathematical data and presentations to an understanding of the real world. Word problems, which make up the main focus of this note, go in the opposite direction. They take the student from a real-world situation to the mathematical model. Even though the setup of a problem may not always be realistic, the word problem is always presented in full sentences with no formulas and no obvious preferences for the right algorithmic approach. The students have to extract the relevant quantitative information for themselves. In this sense, word problems complete the loop in QL.

\footnotetext{
${ }^{9} \mathrm{~A}$ very detailed report on what the various client departments may want from the standard mathematics curriculum may be found in Ganter and Barker (2004).
} 
The word problems that were used in this course were not special in any particular way. In fact they were much simpler than the long word problems found in many standard calculus texts. The latter generally focus on the calculus topic at hand, while Cooper's problems were mainly intended to develop basic analytical thinking. Here is a sampler (numbers in parentheses refer to problem numbers in the text):

- It takes George one hour longer to mow the lawn than it takes Henry. Working together, using two mowers, they can mow the lawn in one hour and twelve minutes. How long would it take Henry to mow the lawn by himself? (11.0.3)

- What amounts of $75 \%$ pure silver and $80 \%$ pure silver should be mixed to obtain 14 grams of $78 \%$ pure silver? (11.0.14)

- A building has a hemispherical roof. The roof is to be painted with a layer of paint one millimeter thick. The radius of the hemisphere is 50 meters. How many liters of paint are needed? (11.0.39)

- In 1990 a fatal disease evolves to which 40\% of a population of five millions trees is susceptible. The proportion of susceptible trees that survive for a period of $t$ years beyond 1990 is $e^{-t}$. Sketch a graph showing how many trees remain during 1990-1995. How quickly is the disease killing off trees at the start of 1992? Give units. When will the population be reduced to $80 \%$ of the level in 1990? (11.0.45)

These examples are a representative sample. In other words, most of the problems assigned in the class did not require calculus knowledge. However they are typical problems that many college-level students still struggle at, and they are precisely the kinds of problems that the client departments want their students to be able to solve.

These problems are also perfect for the purpose of closing the loop in QL: Students need to attack any such problem by extracting out the mathematics in it, solving the mathematical problem and then interpreting the result within the framework of the original problem. Extracting qualitative information from a quantitatively loaded text is a vital skill to develop in our students. ${ }^{10}$ An emphasis on word problems as in the course sequence I had the opportunity to teach also makes sure that our students are able to extract quantitative information. Moreover, by allowing them to practice their basic mathematical skills, such courses will ideally ensure that the students know how to process such information as well.

\footnotetext{
${ }^{10}$ Besides the Sons (1996) report, also see Steen (2001) for the vital importance of QL for a democratic world.
} 
It is safe to assume that once out of our classrooms, most of our students will not be given a polynomial to factor or a function to differentiate to save their lives (then again, check out The Coda). However, many will find themselves in situations where quantitative information will come to them embedded in text, and they will need to extract this information out of the paragraphs, from among the words. Teaching students a systematic way to attack such problems thus will serve to develop their QL skills.

\section{Reflections}

What lessons do I believe I have learned from this teaching experience? I offer the following four. ${ }^{11}$

If a complete $Q L$ program is not feasible, modifying the emphasis of a traditional course (or course sequence) may be a partial solution. Most of us agree with the ideals and goals promoted by the MAA committee report (Sons 1996). In many cases a well-planned QL program is the preferable policy. However, when this approach is not possible or desirable, a modification in emphasis in an already existing course may serve similar purposes.

At UCSB, the university is under certain obligations to offer a calculus course for the students of the client departments. However, if our "main goal is to try to improve problem-solving skills and develop the ability to attack a problem logically, one step at a time, employing reasoning" (Cooper 2000), a purposeful focus on word problems in an otherwise traditional calculus course may be an ultimately successful compromise.

The MATH 34AB sequence uses word problems as a means to the end of developing students' ability to extricate mathematical information from the written word, which coincides perfectly with the aims to provide the students with a path towards quantitative literacy. These courses, therefore, are a good example of a blend of a traditional calculus sequence and a general education sequence emphasizing quantitative literacy for schools that have not developed an independent program for quantitative literacy for various reasons.

\footnotetext{
11 In the following, I discuss some of my observations and make a few comments summarizing things I learned through this teaching experience. Some of these remarks are not essential to the discussion on using word problems as a tool in the path toward quantitative literacy, but they may be relevant to interpret correctly and fully the particular experience I described above. I do not imply that any of my assertions is scientifically tested, and I would be happy to initiate a conversation about any and all the points I make in this section.
} 
At this juncture, the following may be worth stating: It is hard but not impossible to deal with the students' expectation that the class they take will be yet another traditional (calculus) course. Often, students enrolled in a course titled "Calculus" with some qualifications (e.g., Applied Calculus, Integrative Calculus, Calculus for Life Sciences, etc) will expect to learn only what they think "Calculus" should be: techniques of differentiation and integration. This expectation is natural. It does imply, however, that the instructor has to make her plans and reasoning clear to the students if she wants to include some nontraditional features in the course.

In my particular case, most students were uncomfortable at first with the strong emphasis on word problems. However I made sure to emphasize early on and repeated often that the word problems were integral to the goal of our course sequence. I admit that I cannot honestly say that most of the students ended up enjoying word problems and started seeing mathematics differently. However, I do believe that they realized that they were learning some important tools. According to the anonymous survey at the end of the second quarter, some students even came to appreciate our use of word problems in this course. ${ }^{12}$

The general tendency to resist required courses may be alleviated by "home-made" or "made-to-order" courses. It is a very unfortunate but wellknown fact that some students are initially averse to required courses that are not in their majors. Therefore, while teaching the MATH 34AB sequence at UCSB, I frequently reminded the students that the sequence was explicitly designed for UCSB and especially for their majors. I noticed regularly that pointing out this fact helped to relieve the tension a bit. Students seem to appreciate it when they feel that the course was designed with their particular needs in mind. This reaction is encouraging for those looking to develop course sequences custom-made for a particular school or a particular major. ${ }^{13}$

Simplistic and unrealistic word problems may be worthwhile despite being simplistic and unrealistic. I believe that the strength of the word-problems approach is mostly independent of the simplicity of the problems used. Although most of the problems we used did not originate from realistic real-world applications, students could see that some minor variations would indeed show up in their lives. If course developers wish to make use of more-realistic word

\footnotetext{
12 This change was clear in the second survey and in the teaching evaluations. Having graded all the word problems in the midterms and the final, I can also comfortably say that most students figured out how to use the systematic approach sooner or later. Numerical data to support my contention, however, are no longer available.

${ }^{13}$ Clearly just the fact that a course is "home-made" will not in general suffice to suppress all kinds of displeasure: as a colleague reminded me, the fact that "mommy made the spinach only for you" does not always make it more palatable. However, it may still be a cause for more sympathy and understanding.
} 
problems, I believe that they will still need to start with the basics, as many students do not have the expertise to attack even the most simplistic problems. If there is interest among the client departments and cooperation from the mathematics department, developing a problem-solving class may even be more useful than a traditional calculus sequence. ${ }^{14}$

Insisting that students use a fixed format when presenting their solutions helps many students. Throughout the sequence, I required my students to use a fixed format for solutions to the word problems in order to aid weaker students in developing their problem-solving skills by spelling out each step. As expected, some of the stronger students were initially not thrilled by this. They felt that such rules were childish for students as mathematically mature as themselves, and they made sure to let me know about their opinions during office hours.

It turned out, however, that more students were helped by this approach than I expected from the comments I received along the way. Even students who first objected to the format found that it simplified their lives and made their work more presentable, thus helping them get all those coveted partial-credit points when they made a mistake. As we moved further into the sequence, the complaints came to a halt as students got used to the method and saw its benefits.

\section{Conclusion: Interpreting this Note}

I offer this perspective in this quantitative literacy journal as a letter from the trenches, from a calculus instructor to others who might one day find themselves teaching a terminal calculus sequence for non-majors, yet again. I urge mathematics instructors to consider that circumstance to be an opportunity to promote QL. I believe that a simple tool, the word problem, can transform a traditional calculus sequence into one that can develop (the problem-solving verbal-data interpreting form of) QL for the majors of your client departments.

In the research framework suggested by Scheaffer (2008) in the first issue of this journal, this note can perhaps fall into a zeroth component, one where germs of possible research ideas are initiated and brought forth to be presented to researchers and practitioners in the field. In this note, I simply propose that word problems may be a practical tool for students to develop QL skills. Clearly there is more work to be done.

\footnotetext{
${ }^{14}$ Such a course exists in my current institution: MATH 29 at Pomona College is mainly designed for science majors who have a weaker background in quantitative skills. The students taking this course also take calculus; however, this particular course only focuses on problem solving and analytical reasoning.
} 


\section{Coda}

In the second and last anonymous survey of my MATH 34B class, when asked whether they think they will ever benefit from the word problems that they are suffering from, one of the students wrote about yet another Far Side cartoon with St. Peter at the gates of Heaven. I found that in my Far Side album as well, this time on page 266 of the second volume (Larson 2003): The caption reads "Math phobic's nightmare". St. Peter says to the man waiting: "Okay, now listen up. Nobody gets in here without answering the following question: A train leaves Philadelphia at 1:00 p.m. It's traveling at 65 miles per hour. Another train leaves Denver at 4:00... Say, you need some paper?"

\section{Acknowledgments}

I am grateful to the editors and the referees for their useful comments. It was clear to me that each comment was made, very constructively, with the intention to make this into a more scholarly work. I have done my best to incorporate as many of these suggestions as I could.

\section{References}

UCSB. 2004. University of California Santa Barbara General Catalog $2004 / 2005$.

Cooper, D. 2000. Calculus and Mathematical Reasoning for Social and Life Sciences. Dubuque, Iowa: Kendall-Hunt Publishing Co.

Ganter, S. and W. Barker, eds. 2004. The Curriculum Foundation Project, Voices of the Partner Disciplines: A Collection of MAA Committee Reports. Washington DC: Mathematical Association of America. http://www.maa.org/ cupm/crafty/cf project.html.

Larson, G. 2003. The Complete Far Side, 1987-1994, vol.2, Andrews McMeel Publishing.

Madison, B. L. and L.A. Steen. 2008. Evolution of Numeracy and the National Numeracy Network. Numeracy 1(1): article 2. http://dx.doi.org/10.5038/ 1936-4660.1.1.2

Polya, G. 1957. How to Solve It. 2nd ed., Princeton University Press.

Scheaffer, R. L. 2008. Scientifically based research in quantitative literacy: Guidelines for building a knowledge base. Numeracy 1(1): article 3. http:// dx.doi.org/10.5038/1936-4660.1.1.3

Sons, L., ed. 1996. Quantitative Reasoning for College Graduates: A Complement to the Standards. Committee on the Undergraduate Programs in Mathematics (CUPM) Subcommittee on Quantitative Literacy Requirements. Washington 
DC: Mathematical Association of America. http://www.maa.org/past/q1/ q1_ toc.html.

Steen, L. A. ed. 2001. Mathematics and Democracy: The Case for Quantitative Literacy. Princeton NJ: The National Council on Education and the Disciplines. http://www.maa.org/q1/mathanddemocracy.html. 